\title{
Financial Distress Prediction for Small and Medium Enterprises Using Machine Learning Techniques
}

\author{
Aidas Malakauskas $^{1}$, Ausrine Lakstutiene ${ }^{2}$ \\ ${ }^{1}$ Swedbank $A B$ \\ Konstitucijos av. 20A, LT-03502, Vilnius, Lithuania \\ E-mail.aidas.malakauskas@swedbank.lt \\ ${ }^{2}$ Kaunas University of Technology \\ K. Donelaicio st. 73, LT-44029, Kaunas, Lithuania \\ E-mail.ausrine.lakstutiene@ktu.lt
}

cross $^{\text {ref }}$ http://dx.doi.org/10.5755/j01.ee.32.1.27382

\begin{abstract}
Financial distress prediction is a key challenge every financing provider faces when determining borrower creditworthiness. Inherent opaqueness of Small and Medium Enterprise business complicates credit decision making process, therefore increasing cost to finance and lowering probability of receiving funds. This paper used data on 12.000 SMEs to estimate binomial classifiers for financial distress prediction using Logistic Regression, Artificial Neural Networks and Random Forest techniques. Classical financial ratios were used to estimate initial single-period predictors, which were later enhanced with time, credit history and age factors to retrieve multi-period models. Contrary to other studies, financial distress is understood as a significant challenge to company's ability to cover liabilities rather than probability to go bankrupt. Highest prediction accuracy was reached using Random Forest algorithm with additional factors. It was concluded that period-at-risk adjustment is necessary to ensure highest financial distress prediction accuracy.
\end{abstract}

Keywords: Financial Distress Prediction; Random Forest; Artificial Neural Networks; Logistic Regression; Small and Medium Enterprises.

\section{Introduction}

The need of modelling credit risk grew from banks requiring quantitative estimates to calculate necessary capital at risk to support their lending activities. One of the first attempts to impose risk management and minimum capital requirements for financial institutions, was made by introduction of Basel Capital Accord in 1988. Minimum capital requirements were imposed by allotting bank assets one of four risk weights. Due to insufficient granularity, banks started 'shifting risks' and ignoring the underlying risk profile of the debtor. With the introduction of Basel II, a response to criticisms of Basel I, banks could select and use one of two credit risk management techniques: Standardized approach or Internal ratings-based approach (Chatterjee, 2015). This is the first time Small and Medium sized Enterprises (SMEs) received different treatment concerning credit risk in comparison to other corporate entities.

SMEs are the backbone of the world's economy and countries' well-being. One of the biggest challenge SMEs have been facing for the past couple of decades is access to financing. It has become even more prevalent with the introduction of capital requirements, which have put pressure on bank ability to lend. Basel III added an additional burden on banks with an increase on minimal capital ratio (on average from $6 \%$ to $8 \%$ ), which created higher barriers to finance SME companies (Angelkort \& Stuwe, 2011). The importance of SME health on the global economy was emphasized by other studies (Chang et al.,
2016; Berger \& Frame, 2007; 2020; Beck et al., 2008; Zhang et al., 2015; Dietsch \& Petey, 2002; Zhang et al., 2017; Huang et al., 2018; Zhu et al., 2016).

Applying company's creditworthiness evaluation is one of the key topics a lender faces, before deciding, whether the company should be approved for financing. Limited data availability, financial flexibility and lack of clarity are few of many factors, which are complicating creditworthiness evaluation for SMEs, therefore increasing credit risk and cost of financing.

One of the first studies that pioneered modeling credit risk for SMEs was done by Edmister (1972), who created a basic credit evaluation model for legal entities. A significant research related not only to theoretical SME default probability estimation but also to their practical application was carried-out by Altman and Sabato (2007). Their financial distress prediction model for SMEs lead to a reduction in imposed capital requirements by 0.5 p.p. It is evident that: i) SMEs are significantly different from large firms from credit risk perspective; ii) Different procedures should be applied by banks for SMEs not only for application procedures as well as for rating and scoring systems.

The existence of accounting standards, creditor protection schemes and state guarantee programs are factors which positively influence credit availability for SMEs (Berger \& Udell, 2006). Beck et al. (2008) showed that banks, in both developing and developed countries, find SME segment desirable and with good prospects, while also 
indicating the importance and need of governmental programs to support financing (most often through guarantees). Berger and Frame (2007) found that an inclusion of automatic decisions by using Small Business Credit Scoring (SBCS) lending technology for micro-loans of up to $\$ 250.000$ had a positive impact on availability of credit. Findings of Kolari and Shin (2006) showed that lending to SMEs is riskier than to large corporates leading to lower possibility to receive financing. Therefore, financial distress prediction is one of the key topics every lender face, whether determining the financial ability for a borrower to repay the loan or when calculating the capital requirements which are imposed by the financial regulator.

While bankruptcy prediction mainly focuses around predicting the end of a company's lifecycle, with relatively low chance of survival through restructuring, financial distress prediction is a more common occurrence, when a business experiences temporary issues meeting its obligations. Some financial distresses might end-up as bankruptcies but often they are mere setbacks and do not last long. From a lender perspective, when assessing creditworthiness, it is important to identify borrowers which will be able to meet their obligations without experiencing payment difficulties.

Many different authors used various approaches and methodologies for financial distress prediction and received different results varying from extremely high 95\% prediction success which was reached by Altman in his earlier studies (later criticized for biased and over-fitted models), to 'close-to-earth' predictors with results raging from $70 \%$ to $85 \%$ (Ohlson, 1980; Shumway, 2001; Blanco et al., 2015; Ogachi et al., 2020 and others). High variance in results, which have only marginally increased throughout past decade, and continuous search for a better predictor indicates that supplementary tools for financial worthiness evaluation are required.

Even thought, financial distress prediction is a wellstudied topic, there is not enough studies done on SME entities, notably in terms of time factor inclusion and different machine learning technique application. The goal of this paper is to propose a financial distress prediction model, which would include time factors and would forecast SME entity's credit rating's outlook in a 1-year horizon by applying three most promising machine learning techniques. Contrary to previous studies, where probability of default was modelled, this research evaluates credit rating outlook by modelling SME entity financial difficulties, which do not necessarily end-up as bankruptcies or defaults. Instead of using variables that give only one-year financial ratio snapshot - additional time factors are added together with overdue history characteristics, sales and asset change indicators.

The following sections are covered in the paper: literature review, methodology and results, discussion of the key points.

\section{Literature Review}

Studies related to credit risk modelling have significantly grown during the past 50 years, with most notable breakthroughs by Altman (1968) and Merton (1974). For the last 20 years classical modelling techniques have been challenged, as researchers have been discussing modelling credit risk by applying different machine learning techniques (Qu et al., 2019; Atiya, 2001; Pickert, 2017; Shen et al., 2020; Uthayakumar et al., 2020). One of the first machine learning tool application in financial distress prediction was by Atiya (2001) who used Artificial Neural Networks in classic credit risk prediction model developed by Merton (1974). One of key differentiating factors from previous studies was assumed non-linearity of financial distress function. Tsai and $\mathrm{Wu}$ (2008), applied similar approach to classical modelling with additional emphasis on usage of multiple model classifiers. Former were found to overall underperform in comparison to single classifier techniques but performance is not consistent if considering actual Type 1 or Type 2 errors. Specifically, Artificial Neural Networks approach has stood out to be one of the most promising in ensemble modeling tools (Qu et al., 2019; Atiya, 2001; Paliwal \& Kumar, 2009; Boguslauskas \& Mileris, 2009; Bekhet \& Eletter, 2014). Higher model stability for bankruptcy prediction can be reached by using Gaussian Processes, in cases when the dataset suffers high class imbalance (Pena et al., 2011). Credit risk modelling using various machine learning techniques was conducted by a number of studies (Butaru et al., 2016; Addo et al., 2018; Kennedy, 2013; Huang et al., 2018; Zhang et al., 2017; Moscatelli et al., 2020; Gregova et al., 2020; Boughaci et al., 2020), which tried to determine what approaches are most appropriate for specific countries and industries.

Simple machine learning technique - Decision Tree - as a credit classification methodology was started to be used in 1980's, with first studies done by Frydman et al. (1985) and Davis et al. (1992). There are several types of Decision Tree techniques - Random Forests being one of them. Recently, it has been preferred for creditworthiness analysis due to its accuracy and efficiency (Abdelmoula, 2015). One of the first application of Random Forests was covered by Breiman in 2001, who introduced random sampling of trees as well as the idea of tree correlation, his findings showed that for the first-time forest algorithms could compete with arcing approaches not only in classification but also in regression (Breiman, 2001). An independent study done by Sharma (2012) for creditworthiness prediction has shown that the usage of Random Forests increases the accuracy in comparison to Logistic Regression in cases where variables have multicollinearity and complex inter-relationships. Furthermore, Sharma (2012) concluded that Random Forests is a powerful tool for more robust findings, which allows the researchers to assess variable importance and meaning.

SMEs being prone to higher inherent credit risk than larger companies, experience significantly stricter credit worthiness assessment procedures as well as higher collateral requirements (Yoshino \& Taghizadeh-Hesary, 2018). Therefore, to ensure lower barriers to receive financing it is important to ensure state-of-the-art credit worthiness assessment models. In their studies, Hand (2006) and Thomas (2010) concluded that researchers when comparing new model with some reference classifier(s) are prone to a bias, which occurs due to model developers being more adept to their approach and tuning it more elaborately than reference models. By using discriminant and Logit approaches, they found that the 
profitability of SMEs is strongly related to their size, while for large corporates, the relation was opposite. Similar relationship was determined for SME company age, while for large corporates there was close to no impact. Fidrmuc and Hainz (2009) used Probit methodology to study the SME loan market in Slovakia and reported that the results are ambiguous mostly due to strong biases which are related to industry specificity as well as legal-form effects. An analogous study was carried out for German case by Behr and Guttler (2007) who similarly to Fidrmuc and Hainz (2009) concluded that for more indebted companies the probability of default is observed higher. On the other hand, opposite effect comes from higher profitability, which reduces probability of default. German case also showed that the region in which company operates is an important factor when predicting creditworthiness. Most importantly, both studies concluded that SMEs do not present higher credit risk than the large corporate. Yoshino and Taghizadeh-Hesary (2018) determined that for the success of SME loan origination process, one of the most important factors was lender's behavior as well as its credit policy. On the other hand, short-term assets, net income, capital and liquidity metrics, were determined to be key financial indicators for determining general characteristics of SMEs. A wide array of credit risk modelling technique comparison studies was done for Chinese SMEs (Zhang et al., 2015; Zhang et al., 2017; Huang et al., 2018; Zhu et al., 2016, and Chang et al., 2016). Huang et al. (2018) used variations of neural network techniques to determine that Probabilistic Neural Network showed the highest predictive power and had the lowest overall and Type 2 error rates. Zhang et al. (2015) by using state-of-the-art machine learning approaches incorporated Supply Chain Finance (SCF). Similarly, Zhu et al. (2016) compared the performance of Logistic Regression, Artificial Neural Network and their Hybrid models by employing Stress Concentration Factor. His results showed that Type 2 error rate forecasting was lower for Artificial Neural Networks in comparison to Logistic Regression, while the best overall accuracy was reached with the two-stage hybrid model. Shon et al. (2016) by addressing the vagueness of creditworthiness prediction in technology (due to feature linguistic description) proposed the use Fuzzy Logistic Regression. This approach was found to be an appropriate to improve prediction accuracy in comparison to typical Logistic Regression. Addo et al. (2018) built binary classifiers for credit risk prediction using machine learning techniques, including Logistic Regression, Random Forests and Neural Networks. Model estimation used variables taken from company balance, income and cash flow statements, then, first 10 criteria were selected and used to compare their performance across different techniques. Authors observed that the Tree-based classifiers performed better and were more stable than multilayer Artificial Neural Networks. Arora and Kaur (2020) used Bollaso (Bootstrap-Lasso) feature selection technique to select relevant and consistent variables from a pool of variables and applied them to ensembles like Random Forest, Support Vector Machine, Naïve Bayes and k-Nearest Neighbors in order to test the predictive accuracy. Consistently with other studies, Random Forest provided highest accuracy for creditworthiness assessment in comparison to other techniques (Sharma, 2012; Arora \& Kaur, 2020; Teles et al., 2020).

\section{Methodology and Results}

Research covers more than 12-thousand SME company financial statement and credit history data from Baltic states. 23 independent variables were selected for financial distress classification covering two consecutive financial years. Dependent variable was compiled by comparing financial situation for the past financial year to current financial year and based on significant deterioration in credit score. To improve the classification performance, a different approach for variable selection is chosen. Instead of using variables which give only one-year financial ratio snapshot additional time factors are added together with sales and asset change characteristics and overdue history indicator. Process below illustration data collection and modeling set-up (see Figure 1).

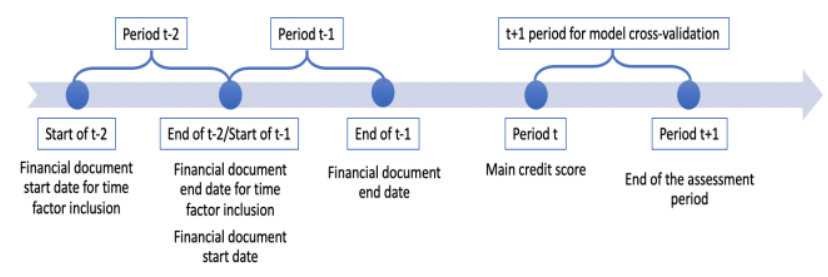

Figure 1. Principles of Data Collection and Model Calculation

Research methodology was formulated using literature review analysis and based on findings from Sharma (2012), Addo et al. (2018) and Arora and Kaur (2020). Financial distress modelling was carried out using three machine learning techniques: Logistic Regression, Artificial Neural Networks and Random Forests.

Research was performed by employing classical and time independent variables as described by Altman and Sabato (2007), Shumway (2001), Bekhet and Eletter (2014), Addo et al. (2018) and Arora and Kaur (2020): i) Profitability (Gross Margin Ratio; Profit Margin Ratio); ii) Liquidity (Current Ratio; Quick Ratio; Cash Ratio); iii) Activity (Accounts Receivable Turnover Ratio); iv) Leverage (Debt to Equity Ratio); v) Coverage (DebtService Coverage Ratio; Asset Coverage Ratio); vi) Change in sales; vii) Change in short - term assets; viii) Historic overdue; $i x$ ) Company age; $x$ ) Country indicator.

Table 1

Independent Variables Used in Model Estimation

\begin{tabular}{|c|c|}
\hline Measure & Metric \\
\hline Profitability & $\begin{array}{l}\text { Gross Margin Ratio= }(\text { Net Sales }- \text { Cost Goods } \\
\text { Sold }) / \text { Net Sales } \\
\text { Profit Margin Ratio }=(\text { Net Sales }- \text { Total } \\
\text { Expenses }) / \text { Net Sales }\end{array}$ \\
\hline Liquidity & $\begin{array}{l}\text { Current Ratio }=\text { Current Assets } / \text { Current } \\
\text { Liabilities } \\
\text { Quick Ratio }=(\text { Cash }+ \text { Marketable Securities }+ \\
\text { Accounts Receivable }) / \text { Current Liabilities } \\
\text { Cash Ratio }=\text { Cash } / \text { Current Liabilities }\end{array}$ \\
\hline Activity & $\begin{array}{l}\text { Accounts Receivable Turnover Ratio = Net } \\
\text { Credit Sales / Average Accounts Receivable }\end{array}$ \\
\hline Leverage & $\begin{array}{l}\text { Debt to Equity Ratio }=[(\text { Short-term Loans })+ \\
(\text { Long term Loans })] / \text { Total Equity }\end{array}$ \\
\hline
\end{tabular}


Ratio, indicated that the average time to retrieve accounts became shorter for SMEs in Latvia and Estonia, while in Lithuania only a slight negative change was recorded. Debt to Equity Ratio contracted in all three countries, with the smallest change in Lithuania at around 1 p.p.

\section{Classification Results Using Classic Variables}

At this stage, only classic variables (Country Code, Current ratio, Quick ratio, Cash ratio, Debt-to-Equity ratio, Gross Margin ratio, Profit Margin ratio, DebtService Coverage ratio, Asset Coverage ratio, Accounts
Receivable Turnover Ratio) were used as specified by Altman and Sabato (2007) Shumway (2001), Bekhet and Eletter (2014) to estimate classifiers using three classification techniques: Logistic Regression, Artificial Neural Networks and Random Forests (Addo et al., 2018). Cut-off values were determined by calculating median values for each model and comparing it to soft-class predictions. Finally, modelling result was assigned corresponding binomial value. For a visual representation of existing class overlap, kernel density estimation of predictions and true classes was prepared.
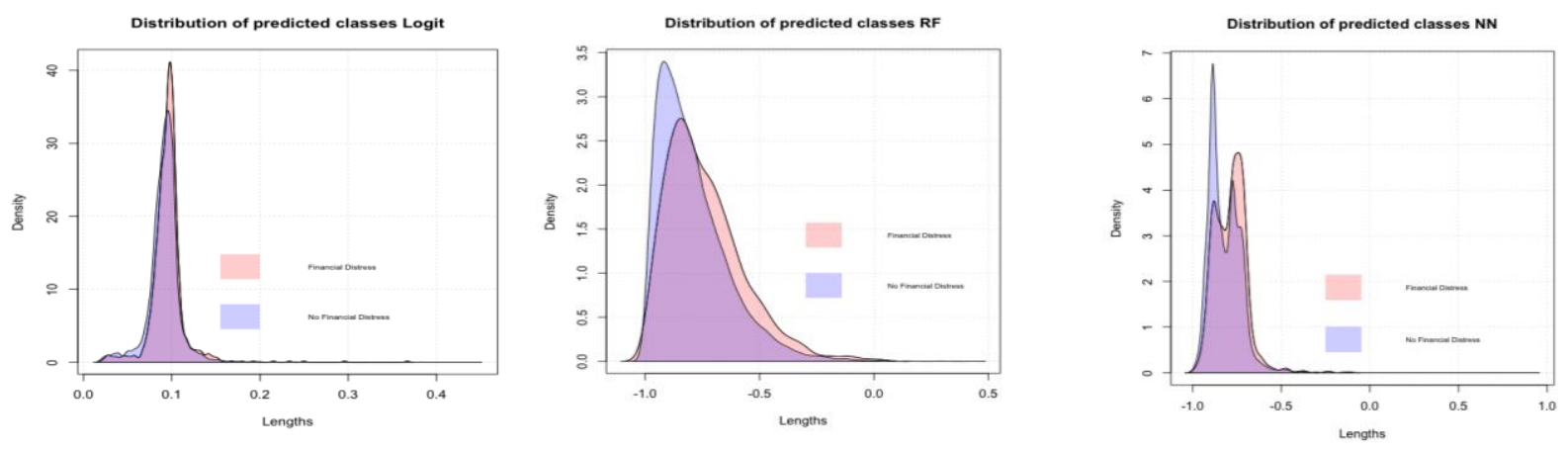

Figure 2. Kernel Density Functions of Predicted and Actual Values for Classic Predictors (Financial Distress - Presented in Orange, No-Financial Distress - Blue)

Evident overlap (see Figure 2) indicates that it was difficult for the classifier to differentiate between the two classes, thus negatively impacting classifier accuracy. This is a common case for imbalanced learning cases like this
(Huang et al., 2016). Set cut-off values were 0.089 for Logistic Regression and -0.80 for both Artificial Neural Networks and Random Forests classifiers.

Table 4

Confusion Matrices for Classic Predictors and Classification Results

\begin{tabular}{|c|c|c|c|c|c|c|c|c|c|}
\hline \multirow[t]{5}{*}{ Actual } & \multicolumn{9}{|c|}{ Predicted } \\
\hline & \multicolumn{3}{|c|}{ Random Forest } & \multicolumn{3}{|c|}{ Logistic Regression } & \multicolumn{3}{|c|}{ Artificial Neural Network } \\
\hline & & False & Positive & & False & Positive & & False & Positive \\
\hline & False & 5630 & 5313 & False & 5593 & 5329 & False & 5649 & 5327 \\
\hline & Positive & 403 & 654 & Positive & 413 & 665 & Positive & 325 & 699 \\
\hline Sensitivity & $61.87 \%$ & & & $60.69 \%$ & & & $65.83 \%$ & & \\
\hline Specificity & $51.28 \%$ & & & $51.11 \%$ & & & $51.58 \%$ & & \\
\hline False Alarm & $38.17 \%$ & & & $39.29 \%$ & & & $34.20 \%$ & & \\
\hline Misses & $48.68 \%$ & & & $48.89 \%$ & & & $48.38 \%$ & & \\
\hline Class Accuracy & $52.25 \%$ & & & $52.01 \%$ & & & $52.89 \%$ & & \\
\hline Avg. Class Accuracy & $56.59 \%$ & & & $55.91 \%$ & & & $58.69 \%$ & & \\
\hline Harmonic Mean & $56.10 \%$ & & & $55.50 \%$ & & & $57.82 \%$ & & \\
\hline
\end{tabular}

Highest predictor accuracy based on harmonic mean and considering set cut-off values was for Artificial Neural Networks classifier $-57.82 \%$. The performance of Logistic Regression and Random Forests techniques was lower by 2.32 and 1.72 p.p. accordingly. Notably, sensitivity, ratio which identifies the proportion of true positives and is one of the key factors in evaluating classifier performance when classifying imbalanced datasets was highest for Artificial Neural Networks technique.

To evaluate predictor performance for all possible cutoff values, ROC and DET graphs are in the Figure 3. 

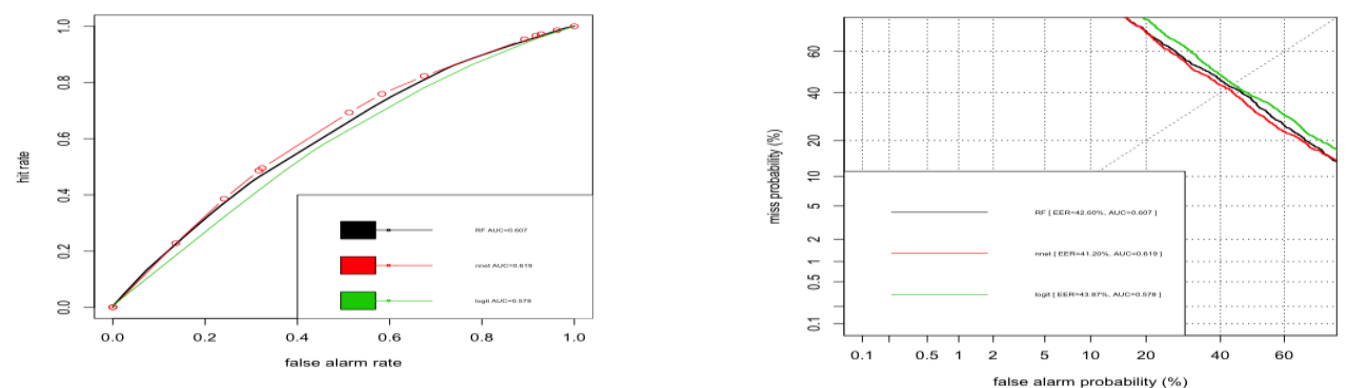

Figure 3. ROC and DET Graphs for Classic Predictors

(Logistic Regression presented in green, Random Forests - black, Artificial Neural Networks - red)

Overall classifier performance throughout all possible cut-offs was consistent with results from single value cutoffs. Best generalization results were shown by Artificial Neural Networks classifier with AUC and EER values of 0.62 and $41 \%$. Random Forests classifier was able to outperform Artificial Neural Networks at extreme cut-offs, but overall accuracy was slightly lower with AUC at 0.61 and EER at 43 $\%$. In both cases, worst prediction accuracy was with using Logistic Regression (AUC=0.58, EER= $44 \%$ ).

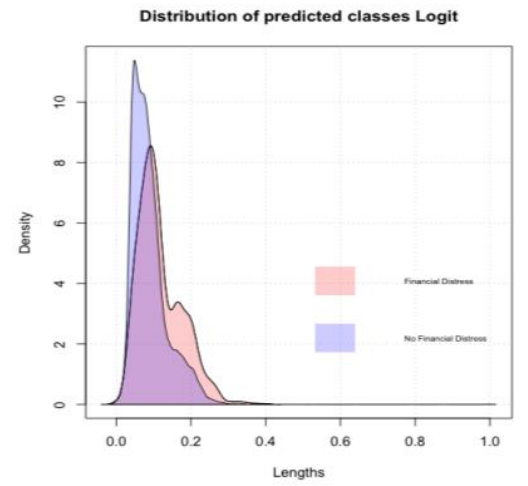

\section{Classification Results With time Factors}

In the next stage, models were enhanced with time and supplementary financial distress indicators. Addition of variables enriched the predictor with a wider perspective, which consists of lagged classical variables, Historic overdue, Company Age, Change in sales, Change in short - term assets, Country indicator.

Figure 4. Graphs Representing Kernel Density Functions of Predicted and Actual Values for pan-Baltic Predictors with Additional Time Factors (Financial Distress Represented in Orange, No-Financial Distress - Blue)

As shown in Figure 4, true and predicted class overlap was slightly lower in comparison to classic classifiers, while challenges related to imbalanced case prediction remained evident. Set cut-off values in comparison to classic predictors remained relatively the same (Logistic Regression: 0.08, Artificial Neural Networks: -0.81, Random Forests: - 0.83). As noted by Shumway (2001) period-at-risk adjustment has a positive effect on classifier performance.

Table 5

Confusion Matrices for Pan-Baltic Predictors with Additional Factors and Classification Results

\begin{tabular}{|c|c|c|c|c|c|c|c|c|c|}
\hline \multirow[t]{5}{*}{ Actual } & \multicolumn{9}{|c|}{ Predicted } \\
\hline & \multicolumn{3}{|c|}{ Random Forest } & \multicolumn{3}{|c|}{ Logistic Regression } & \multicolumn{3}{|c|}{ Artificial Neural Network } \\
\hline & & False & Positive & & False & Positive & & False & Positive \\
\hline & False & 5860 & 5345 & False & 5836 & 5369 & False & 5711 & 5494 \\
\hline & Positive & 318 & 817 & Positive & 33418 & 801 & Positive & 459 & 676 \\
\hline Sensitivity & $72.03 \%$ & & & $70.61 \%$ & & & $59.61 \%$ & & \\
\hline Specificity & $52.32 \%$ & & & $51.99 \%$ & & & $51.01 \%$ & & \\
\hline False Alarm & $27.99 \%$ & & & $29.40 \%$ & & & $40.46 \%$ & & \\
\hline Misses & $47.68 \%$ & & & $47.89 \%$ & & & $49.21 \%$ & & \\
\hline Class Accuracy & $54.15 \%$ & & & $53.77 \%$ & & & $51.82 \%$ & & \\
\hline $\begin{array}{ll}\text { Avg. } & \text { Class } \\
\text { Accuracy } & \end{array}$ & $62.11 \%$ & & & $61.29 \%$ & & & $55.33 \%$ & & \\
\hline Harmonic Mean & $60.61 \%$ & & & $59.89 \%$ & & & $54.92 \%$ & & \\
\hline
\end{tabular}


With the addition of new independent variables and based on selected cut-off values, highest accuracy predictor became Random Forests. For it, harmonic mean improved by 2.79 p.p. to highest value of $60.61 \%$. Sensitivity ratio improved by 10.16 p.p. to $72.3 \%$. An improvement in harmonic mean was also noticed for

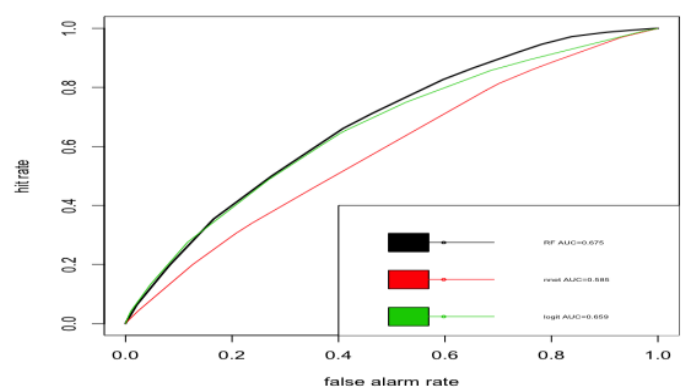

Logistic Regression classifier, which improved by 4.39 p.p. to $59.89 \%$. Best performing predictor using classic variables - Artificial Neural Networks, had a much worse overall results - harmonic mean decreased by 2.9 p.p. to $54.92 \%$ and sensitivity fell by 6.22 p.p. to $59.61 \%$.

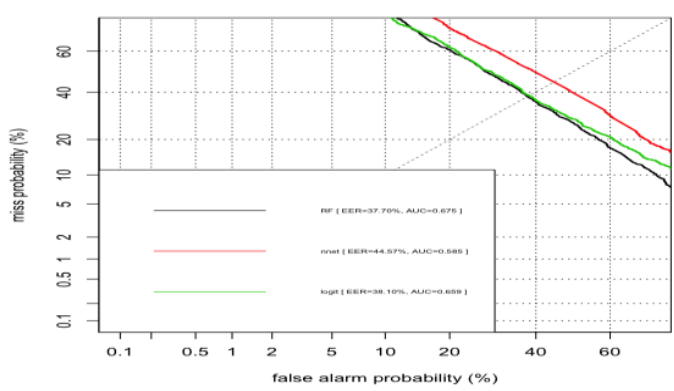

Figure 5. ROC and DET Graphs for Classifiers with Additional Factors

(Logistic Regression presented in green, Random Forests - black, Artificial Neural Networks - red)

Just like for set cut-off value, most accurate financial distress prediction technique was Random Forests, with AUC value of 0.68 and EER - $38 \%$. A close runner-up was Logistic Regression, with AUC - 0.66 and EER - $38 \%$. Addition of new independent variables had a negative impact on Artificial Neural Networks predictor, which had a lower AUC (-0.03) and higher EER (+4 p.p.) result. Artificial Neural Networks was the worst predictor when using additional factors.

\section{Table 6}

Classification Results for Financial Distress Predictors

\begin{tabular}{lcccc}
\hline Models & \multicolumn{2}{c}{ Only classic ratios } & \multicolumn{2}{c}{$\begin{array}{c}\text { With additional } \\
\text { factors }\end{array}$} \\
\hline & AUC & EER & AUC & EER \\
\cline { 2 - 5 } $\begin{array}{l}\text { Random } \\
\begin{array}{l}\text { Forests } \\
\text { Logistic }\end{array}\end{array}$ & 0.61 & $43 \%$ & $\mathbf{0 . 6 8}$ & $\mathbf{3 8 \%}$ \\
$\begin{array}{l}\text { Regression } \\
\text { Artificial } \\
\text { Neural } \\
\text { Network }\end{array}$ & 0.58 & $44 \%$ & 0.66 & $38 \%$ \\
\hline
\end{tabular}

Logistic Regression and Random Forests predictors experienced an increase in classification accuracy with the introduction of additional variable. Overall best performing financial distress predictor with highest AUC and lowest EER was Random Forests.

Comparably to regular regression beta values, Random Forests is also able to identify relative variable importance by indicating numbers of cases which would have been misclassified, provided a variable was omitted from the classifier.
Table 7

Variable Importance for Financial Distress Prediction with Time Variables using Random Forests

\begin{tabular}{|c|c|c|}
\hline Variable & Period & Importance \\
\hline Country code & Financial year & 9 \\
\hline Historic Overdue & Financial year & 18 \\
\hline $\begin{array}{l}\text { Accounts Receivable } \\
\text { Turnover Ratio }\end{array}$ & Last Fin. year & 43 \\
\hline Profit Margin Ratio & Financial year & 46 \\
\hline $\begin{array}{l}\text { Accounts Receivable } \\
\text { Turnover Ratio }\end{array}$ & Financial year & 47 \\
\hline Current Ratio & Last Fin. year & 49 \\
\hline Current Ratio & Financial year & 50 \\
\hline Debt to Equity Ratio & Financial year & 51 \\
\hline Quick Ratio & Last Fin. year & 51 \\
\hline Quick Ratio & Financial year & 52 \\
\hline Gross Margin Ratio & Last Fin. year & 53 \\
\hline Debt to Equity Ratio & Last Fin. year & 54 \\
\hline $\begin{array}{l}\text { Debt-Service Coverage } \\
\text { Ratio }\end{array}$ & Financial year & 54 \\
\hline $\begin{array}{l}\text { Debt-Service Coverage } \\
\text { Ratio }\end{array}$ & Last Fin. year & 55 \\
\hline Profit Margin Ratio & Last Fin. year & 55 \\
\hline Asset Coverage Ratio & Last Fin. year & 55 \\
\hline Asset Coverage Ratio & Financial year & 55 \\
\hline Cash Ratio & Last Fin. year & 56 \\
\hline $\begin{array}{l}\text { Change in short - term } \\
\text { assets }\end{array}$ & Financial year & 63 \\
\hline Cash Ratio & Financial year & 64 \\
\hline Change in sales & Financial year & 65 \\
\hline Company Age & Financial year & 78 \\
\hline
\end{tabular}

Company age was deemed to be the most important variable having direct impact on correctly classified cases (78). Importance of age as a variable was also noted by Bekhet and Eletter (2014), and Arora and Kaur (2020). On the other hand, company's country did not have a significant impact on classifier performance. Majority of variables had a uniform impact ranging from 43 to 65 cases, indicating that no clear group of indicators (or periods) can be specifically outlined. 


\section{Conclusions and Discussion}

Modelling credit risk is one of the major topics every lender face, whether determining the financial ability for a borrower to repay the loan or when calculating the capital requirements which are imposed by the financial regulator. This task becomes even harder, when SME specific factors like limited data availability and financial flexibility are introduced.

To reflect actual lender credit decision making frameworks and contrary to ordinary probability of default predictors, dependent variable was specified by classifying financial distress when an SME entity faces financial difficulties and not necessarily reaches final stages of bankruptcy. Classical financial ratios, proposed by Altman and Sabato (2007), Shumway (2001), Bekhet and Eletter (2014), were used for selecting independent variables, which consist of country identifier and financial variables from financial strength evaluation categories like Liquidity, Leverage, Profitability, Coverage and Activity. The best performing financial distress predictor using single-period classical ratio inputs was Artificial Neural Networks, which had the highest AUC value of 0.62 and lowest EER of $41 \%$. The model was able to correctly classify $66 \%$ of actual financial distress cases.

To further improve classification performance - new independent variables were included. As noted by Shumway (2001), instead of using variables which give only one-year financial ratio snapshot - additional year time factors were added together with overdue history, changes in asset and sale characteristics. This addition improved predictor sensitivity by 6 p.p. to $72 \%$ for the best classifier - Random Forests, with highest AUC value of 0.68 and lowest EER of $38 \%$. Contrary to Random Forests, the best performing methodology for a staticperiod classification - Artificial Neural Networks experienced deterioration in prediction sensitivity by 6 p.p. Mixed classifier response to time factors might be related to the empirical nature of model development, which can vary from variables to training technique differences (Addo et al., 2018; Arora \& Kaur; 2020). Overall, multiperiod classification was a superior approach in comparison to a static-period predictor, which shows that time factors did reduce the uncertainty factor by correcting for period-at-risk.

Individual variable importance, in the best performing Random Forests classifier with additional factors, was similar throughout majority of variables. Highest importance was associated to company age and lowest to country indicator. Relatively small importance numbers for individual variables, indicate that the main classifier strength is related to inter-connections between all variables and not stand-alone factors.
Estimated financial distress predictor, if compared to conventional probability of default classifiers, had slightly lower prediction power of $72 \%$. In comparison, other probability of default modelling studies had accuracy as high as $85 \%$ (even after correcting for bias). Possible reasons for lower estimator accuracy, could be linked to different dependent variable formulation. Classical credit risk prediction models are focused on the fact of bankruptcy (or default), while in this study financial distress is considered when an SME entity begins having economic problems, as specified by changes in credit scores. Bankruptcy being a culminating event in company's existence, very rarely happens more than once and it takes more than one factor to trigger. On the other hand, company could experience multiple financial distress events without triggering a bankruptcy. For example, events like court disputes, closed working capital facilities, changes in personnel can be reasons for temporary financial shocks, even for companies which previously indicated low probability of default. From lender's perspective, depending on its risk appetite, neither of the two would be preferred due to potentially higher capital requirements.

Recent events related to COVID-19 outbreak have shown the importance of improving credit risk prediction. Based on European Central Bank report, if comparing to 2019 May, one of the Baltic country's (Lithuania), corporate financing portfolio shrank by $7.7 \%$, which is more than $700 \mathrm{mln}$. euros. This is the biggest corporate financing portfolio drop in the Euro Zone. Carried out study contributes to existing literature on creditworthiness assessment by implementing a combination of variables with multiple forecasting techniques in the Baltic State market. Estimated model should make it easier for decision makers to assess SME creditworthiness by emphasizing importance of time factors and appropriate forecasting model selection, thus creating a positive impact on lender bottom-line through lower total capital requirements. A reduction in relative cost of capital for major lenders should positively improve SME entity access to financing.

Methodology of financial distress prediction presented in this paper can be used as a tool to enhance financing provider decision making frameworks by adding insights to company financial outlook and by lowering probability to experience unexpected losses.

\section{Acknowledgement}

This study would not have been possible without the contribution of Swedbank $\mathrm{AB}$, which kindly shared anonymized SME company data for its three Baltic state markets. Thank you for the trust and support.

\section{References}

Abdelmoula, A. K. (2015). Bank credit risk analysis with k-nearestneighbor classifier: Case of Tunisian banks. Accounting and Management Information Systems, 14 (1), 79-106.

Addo, P. M., Guegan, D., \& Hassani, B. (2018). Credit Risk Analysis Using Machine and Deep Learning Models. Risks, 6 (38), 1-19. https://doi.org/10.3390/risks6020038 
Altman, E. I. (1968). Financial Ratios, Discriminant Analysis and the Prediction of Corporate Bankruptcy. The Journal of Finance, 23 (4), 589-609. Available from internet: https://www.jstor.org/stable/pdf/2978933.pdf; https://doi.org/ 10.1111/j.1540-6261.1968.tb00843.x

Altman, E. I., \& Sabato, G. (2007). Modeling Credit Risk for SMEs: Evidence from the US Market. ABACUS, 43 (3), 332-347. https://doi.org/10.1111/j.1467-6281.2007.00234.x

Angelkort, A., \& Stuwe, A. (2011). Basel III and SME Finacing. Managerkreis der Friedrich-Ebert-Stiftung.

Arora, N., \& Kaur, P. D. (2020). A Bolasso based consistent feature selection enabled random forest clssification algoritm: An application to credit risk assessment. Applied Soft Computing Journal, 86, 1-15. https://doi.org/ 10.1016/j.asoc.2019.105936

Atiya, A. F. (2001). Bankruptcy Prediction for Credit Risk Using Neural Networks: A Survey and New Results. IEEE Transactions in Neural Networks, 12 (4), 929-935. https://doi.org/10.1109/72.935101

Beck, T., Demirguc-Kunt, A., \& Martinez Peria, M. S. (2008). Banking SMEs Around the World: Lending Practices, Business Models, Drivers and Obstacles. Access Finance, 1 (26), Available from internet: https://www.researchgate.net/publication/23970207_Bank_Financing_for_SMEs_Around_the_World_Drivers_Obst acles_Business_Models_and_Lending_Practices; https://doi.org/10.1596/1813-9450-4785

Behr, P., \& Guttler, A. (2007). Credit Risk Assessment and Relationship Lending: An Empirical Analysis of German Small and Medium-Sized Enterprises. Journal of Small Business Management, 45 (2), 194-213. https://doi.org/10. 1111/j.1540-627X.2007.00209.x

Bekhet, H. A., \& Eletter, S. F. K. (2014). Credit risk assessment model for Jordanian commercial banks: Neural scoring approach. Review of Development Finance, 4, 20-28. https://doi.org/10.1016/j.rdf.2014.03.002

Berger, A. N., \& Frame, S. W. (2007). Small Business Credit Scoring and Credit Availability. Journal of Small Business Management, 45 (1), 5-22. https://doi.org/10.1111/j.1540-627X.2007.00195.X

Berger, A. N., \& Frame, S. W. (2020). Small Business Credit Scoring and Credit Availability. Journal of Small Business Management, 45 (1), 5-22. https://doi.org/10.1111/j.1540-627X.2007.00195.x

Berger, A. N., \& Udell, G. F. (2006). A More Complete Conceptual Framework for SME Finance. Journal of Banking \& Finance, Elsevier, vol. 30(11), 2945-2966. https://doi.org/10.1016/j.jbankfin.2006.05.008

Blanco, A., Irimia, A., Oliver, M. D., \& Wilson, N. (2015). Improving Bankruptcy Prediction in Micro-Entities by Using Nonlinear Effects and Non-Financial Variables. Finance a uver-Czech Journal of Economics and Finance, 65 (2), $144-166$.

Boguslauskas, V., \& Mileris, R. (2009). Estimation of credit risk by artificial neural networks models. Inzinerine Ekonomika-Engineering Economics, (4), 7-14.

Boughaci, D., Alkhawaldeh, A. A. K., Jaber, J. J., \& Hamadneh, N. (2020). Classification with segmentation for credit scoring and bankruptcy prediction. Empirical Economics, 01, 1-29. https://doi.org/10.1007/s00181-020-01901-8

Breiman, L. (2001). Random Forests. Statistics Department. Berkeley: University of California. Available from internet: https://www.stat.berkeley.edu/ breiman/randomforest2001.pdf

Butaru, F., Chen, Q., Clark, B., Das, S., Lo, A. W., \& Siddique, A. (2016). Risk and Risk Management in the Credit Card Industry. Journal of Banking and Finance, 72, 218-239. https://doi.org/10.1016/j.jbankfin.2016.07.015

Chang, Y.C., Chang, K.H., Chu, H.H., \& Tong, L.I. (2016). Establishing decision tree-based short-term default credit risk assessment models. Communications in Statistics, 45 (23), 6803-6815. https://doi.org/10.1080/03610926. $\underline{2014.968730}$

Chatterjee, S. (2015). Modelling credit risk. London: Bank of England. Available from internet: https://www.bankofengland.co.uk/-/media/boe/files/ccbs/resources/modelling-credit-risk

Davis, R. H., Edelman, D. B., \& Gammerman, A. J. (1992). Machine-learning algorithms for credit-card applications. Journal of Management and Mathematics, 4 (1), 43-51. Available from internet: https://academic.oup.com/imaman/ article-abstract/4/1/43/656001?redirectedFrom=fulltext; https://doi.org/10.1093/imaman/4.1.43

Demsar, J. (2006). Statistical Comparisons of Classifiers over Multiple Data Sets. Journal of Machine Learning Research, $7,1-30$

Dietsch, M., \& Petey, J. (2002). The credit risk in SME loans portfolios: Modeling issues, pricing, and capital requirements. Journal of Banking and Finance, 2/3, (26), 303-322. https://doi.org/10.1016/S0378-4266(01)00224-2

Drummond, C. (2006). Statistical Comparisons of Classifiers over Multiple Data Sets. Ontario: National Research Council Canada. 
Edmister, R. O. (1972). Finnacial ratios as discriminant predictors of small business failure. The Journal of Finance, 27 (1), 139-140. Available from internet: https://onlinelibrary.wiley.com/doi/epdf/10.1111/j.1540-6261.1972. tb00633.x; https://doi.org/10.1111/j.1540-6261.1972.tb00633.x

Fidrmuc, J., \& Hainz, Ch. (2009). Default Rates in the Loan Market for SMEs: Evidence from Slovakia. Ifo Institute Leibniz Institute for Economic Research, Ifo Working Paper No. 72. Ifo Institute - Leibniz Institute for Economic Research. Available from internet: https://www.econstor.eu/bitstream/10419/73730/1/IfoWorkingPaper-72.pdf

Frydman, H., Altman, E. I., \& Kao, D. L. (1985). Introducing Recursive Partitioning for Financial Classification: The Case of Financial Distress. The Journal of Finance, 40 (1), 269-291. Available from internet: https://onlinelibrary. wiley.com/doi/abs/10.1111/j.1540-6261.1985.tb04949.x; https://doi.org/10.1111/j.1540-6261.1985.tb04949.x

Gregova, E., Valaskova, K., Adamko, P., Tumpach, M., \& Jaros, J. (2020). Predicting Financial Distress of Slovak Enterprises: Comparison of Selected Traditional and Learning Algorithms Methods. Sustainability, 12 (3954), 1-17. https://doi.org/10.3390/su12103954

Hand, D. J. (2006). Classifier Technology and the Illusion of Progress. Statistical Science, 21 (1), 1-15. https://doi.org/10.1214/088342306000000060

Huang, X., Liu, X., \& Ren, Y. (2018). Enterprise credit risk evaluation based on neural network algorithm. Cognitive Systems Research, 52, 317-324. https://doi.org/10.1016/j.cogsys.2018.07.023

Japkowicz, N., \& Shah, M. (2011). Evaluating Learning Algorithms: A Classification Perspective. Cambridge University Press. https://doi.org/10.1017/CBO9780511921803

Kennedy, K. (2013). Credit Scoring Using Machine Learning. Doctoral thesis. Technological University Dublin. Available from internet: https://arrow.tudublin.ie/sciendoc/137/

Kolari, J. W., Ou, C. C., \& Shin, H. G. (2006). Assessing the Profitability and Riskiness of Small Business Lenders in the Banking Industry. Journal of Entrepreneurial Finance and Business Ventures, 11 (2), 1-26. https://doi.org/ $\underline{10.2139 / \mathrm{ssrn} .1017093}$

Merton, R. C. (1974). On the Pricing of Corporate Debt: The Risk Structure of Interest Rates. Journal of Finance, 29 (2), 449-470. Available from internet: https://onlinelibrary.wiley.com/doi/10.1111/j.1540-6261.1974.tb03058.x; https://doi.org/10.1111/j.1540-6261.1974.tb03058.x

Moscatelli, M., Parlapiano, F., Narizzano, S., \& Viggian, G. (2020). Corporate default forecasting with machine learning. Expert Systems with Applications, 161 (11356), 1-12. https://doi.org/10.1016/j.eswa.2020.113567

Ogachi, D., Richard Ndege, R., Gaturu, P., \& Zoltan, Z. (2020). Corporate Bankruptcy Prediction Model, a Special Focus on Listed Companies in Kenya. Journal of Risk Financial Management, 13 (47), 1-14. https://doi.org/10. $\underline{3390 / j \mathrm{rfm} 13030047}$

Ohlson, J. A. (1980). Financial Ratios and the Probabilistic Prediction of Bankruptcy. Journal of Accounting Research, 18 (1), 109-131. Available from internet: https://www.jstor.org/stable/2490395?seq=1\#metadata_info_tab_contents; https://doi.org/10.2307/2490395

Paliwal, M., \& Kumar, U. A. (2009). Neural networks and statistical techniques: A review of applications. Expert Systems with Applications, 36, 2-17. https://doi.org/10.1016/j.eswa.2007.10.005

Pickert, J. (2017). Risk assessment of unsecured loans - example of entering a new market. Central European Review of Economics and Management, 1 (3), 45-65. https://doi.org/10.29015/cerem.449

Qu, Y., Quan, P., Lei, M., \& Shi, I. (2019). Review of bankruptcy prediction using machine learning and deep learning techniques. Procedia Computer Science, 162, 895-899. https://doi.org/10.1016/j.procs.2019.12.065

Sharma, D. (2012). Improving the Art, Craft and Science of Economic Credit Risk Scorecards Using Random Forests: Why Credit Scorers and Economists Should Use Random Forests. Academy of Banking Studies Journal, 11 (1), $93-$ 117. Available from internet: https://www.abacademies.org/articles/volume-11-issue-1.pdf

Shen, F., Wang, R., \&, Shen, Y. (2020). A cost-sensitive logistic regression credit scoring model based on multi-objective optimization approach. Technological and Economic Development of Economy, 26 (2), 405-429. https://doi.org/10. $\underline{3846 / \text { tede.2019.11337 }}$

Shmueli, G., Patel, N. R., \& Bruce, P. C. (2005). Data Mining In Excel: Lecture Notes and Cases. Arlington: Resampling Stats, Inc.

Shumway, T. (2001). Forecasting Bankruptcy More Accurately: A Simple Hazard Model. The Journal of Business, 74 (1), 101-124. https://doi.org/10.1086/209665 
Sun, J., Lang, J, Fujita, H., \& Li, H. (2018). Imbalanced enterprise credit evaluation with DTE-SBD: Decision tree ensemble based on SMOTE and bagging with differentiated sampling rates. Information Sciences, 425, 76-91. https://doi.org/10.1016/j.ins.2017.10.017

Teles, G., Rodrigues, J. J. P., Rabelo, R. A. L., \& Kozlov, S. A. (2020). Comparative study of support vector machines and random forests machine learning algorithms on credit operation. Journal of Software: Practice and Experience, Special Issue, 1-9. Available from internet: https://onlinelibrary.wiley.com/doi/epdf/10.1002/spe.2842; https://doi.org/10.1002/spe.2842

Thomas, L. C. (2010). Consumer Finance: Challenges for Operational Research. The Journal of the Operational Research Society, 61 (1), 41-52. https://doi.org/10.1057/jors.2009.104

Tsai, C.-F., \& Wu, J.-W. (2008). Using neural network ensembles for bankruptcy prediction and credit scoring. Expert Systems with Applications, 34 (4), 2639-2649. https://doi.org/10.1016/j.eswa.2007.05.019

Uthayakumar, J., Metawa, N., Shankar, K, \& Lakshmanaprabu, S.K. (2020). Financial crisis prediction model using ant colony optimization. International Journal of Information Management, 50, 538-556. Available from internet: https://www.sciencedirect.com/science/article/pii/S0268401218310910; https://doi.org/10.1016/j.ijinfomgt.2018.12.001

Visa, S., Ramsay, B., Ralescu, A., \& VanDerKnaap, E. (2011). Confusion Matrix-based Feature Selection. Proceedings of The 22nd Midwest Artificial Intelligence and Cognitive Science Conference, 120-127.

Yoshino, N., \& Taghizadeh-Hesary, F. (2018). A Comprehensive Method for the Credit Risk Assessment of Small and Medium-Sized Enterprises Based on Asian Data. ADBI Working Paper 907. Tokyo: Asian Development Bank Institute. Available from internet: https://www.adb.org/publications/comprehensive-method-credit-risk-assessmentsmebased-asian-data; https://doi.org/10.4324/9780429401060-3

Zhang, L., Hu, H., \& Zhang, D. (2015). A credit risk assessment model based on SVM for small and medium enterprises in supply chain finance. Financial Inovations, 1 (14), 1-21. Available from internet: https://link.springer.com/ content/pdf/10.1186/s40854-015-0014-5.pdf; https://doi.org/10.1186/s40854-015-0014-5

Zhang, X., Zhao, X., \& and N. Wu, N. (2017). Credit risk assessment model for cross-border e-commerce in a BP neural network based on PSO-GA. Agro Food Industry Hi Tech, 28 (1), 411-414.

Zhou, L. (2013). Performance of corporate bankruptcy prediction models on imbalanced dataset: The effect of sampling methods. Knowledge-Based Systems, 41, 16-25. https://doi.org/10.1016/j.knosys.2012.12.007

Zhu, Y., Xie, C., Sun, B., Wang, G. J., \& Yan, X. G. (2016). Predicting China's SME Credit Risk in Supply Chain Financing by Logistic Regression, Artificial Neural Network and Hybrid Models. Sustainability, 8 (5), 1-17. Available from internet: https://www.mdpi.com/2071-1050/8/5/433; https://doi.org/10.3390/su8050433

\section{Authors' biographies}

Aidas Malakauskas is a candidate for Ph.D. in economics in Kaunas University of Technology and working in AB Swedbank as the Head of Financing Transformation Department. He is also a member of Sustainable Economics Research Group in School of Economics and Business at Kaunas University of Technology. Research interests are in the areas of credit risk, SMEs, access to finance, credit rationing, and machine learning.

Aušrinė Lakštutienė is a Ph.D. in economics and an associate professor at Kaunas University of Technology. She is also a committee member in the Finance study programme, member of the Sustainable Economics Research Group, School of Economics and Business, Kaunas University of Technology. Research interests are in the areas of risk management, insurance risk, financial services, financial services development, and business financing sources.

The article has been reviewed.

Received in July 2020; accepted in February 2021.

This article is an Open Access article distributed under the terms and conditions of the Creative Commons Attribution 4.0 (CC BY 4.0) License (http://creativecommons.org/licenses/by/4.0/). 